\title{
GMR
}

\section{Study of the genetic diversity and structure of a natural population of Nectandra megapotamica (Spreng.) Mez. using RAPD markers}

\author{
L.S. Costa ${ }^{1}$, L.R.S. Reiniger ${ }^{1}$, B.M. Heinzmann ${ }^{2}$, L.P. Amaral ${ }^{2}$ and C.M.L. Serrote ${ }^{1}$ \\ ${ }^{1}$ Núcleo de Biotecnologia e Melhoramento, Departamento de Fitotecnia, \\ Universidade Federal de Santa Maria, Santa Maria, RS, Brasil \\ ${ }^{2}$ Laboratório de Extrativos Vegetais, Departamento de Ciências Florestais, \\ Universidade Federal de Santa Maria, Santa Maria, RS, Brasil \\ Corresponding author: L.R.S. Reiniger \\ E-mail: liarsr@ufsm.br
}

Genet. Mol. Res. 14 (4): 18407-18413 (2015)

Received August 21, 2015

Accepted October 28, 2015

Published December 23, 2015

DOI http://dx.doi.org/10.4238/2015.December.23.28

ABSTRACT. Nectandra megapotamica (Spreng.) Mez. is a tree species that naturally occurs in the Atlantic Forest, Brazil. The aim of this study was to evaluate the genetic diversity and structure of a natural population of $12 N$. megapotamica individuals using random amplified polymorphic DNA markers. Eleven primers were used in this study, producing 81 bands, of which $98.99 \%$ were polymorphic. Analysis using STRUCTURE defined three different clusters $(K=3)$, results that were consistent with those of principal coordinates analysis. Both Nei's genetic diversity $(h=0.33$ ) and Shannon's diversity index $(I=0.49)$ were relatively high. Analysis of molecular variance indicated that $24.89 \%$ of the genetic variability was among clusters, while the remaining $75.11 \%$ was within clusters. The Mantel test showed a weak correlation between genetic and geographic distances $(r=0.25, \mathrm{P}=0.105)$. Overall, the results revealed high levels of genetic diversity within clusters and high genetic differentiation among 
clusters without any spatial pattern of genetic variability. In addition, gene flow was independent of the geographical distribution and was compatible with the hierarchical island model.

Key words: PCR; Genetic parameters; Forestry species

\section{INTRODUCTION}

The Atlantic Forest biome is one of the world's major hotspots of biodiversity. Previous studies indicated that the flora of this biome consists of approximately 20,000 known species, including about 8,000 endemic species (Mittermeier et al., 1998). Among the native species of the Atlantic Forest, those belonging to the Lauraceae family are all woody plants with high economic value for timber and essential oils.

Nectandra megapotamica (Spreng.) Mez. (Lauraceae), commonly known as canelapreta, is found in the south, southeast, and central regions of Brazil. This species is widely used in folk medicine for its antirheumatic, anti-inflammatory, and analgesic properties. As previous phytochemical studies have shown, these properties are due to the presence of phenylpropanoids (Garcez et al., 2009), tetrahydrofuran lignans, and alkaloids (Dos Santos and Gilbert, 1975). Additionally, Apel et al. (2006) suggested that the essential oils of $N$. megapotamica have pharmacological potential due to their antitumor activity and antimicrobial activity against Staphylococcus aureus. Environmental factors such as seasonality, temperature, water availability, radiation, nutrient availability, altitude, and atmospheric pollution can significantly alter the biological activity of various extractives; however, the chemical composition of essential oils is mainly determined by genetic factors (Gobbo-Neto and Lopes, 2007).

Molecular markers are an important tool for evaluating genetic diversity within and among species and populations. Compared to other polymerase chain reaction (PCR) markers, Random Amplified Polymorphic DNA (RAPD) markers have several advantages; they are easy, affordable, quick to assay, and require only small amounts of DNA (Bered et al., 1997). The assessment of genetic diversity in natural populations is important for the study of speciation in the tropical forests and the conservation of genetic resources (Buckley et al., 1988). The objective of the present study was to assess the diversity and characterize the genetic structure of a natural N. megapotamica population from the central region of Rio Grande do Sul state, Brazil, using RAPD markers.

\section{MATERIAL AND METHODS}

\section{Plant material and DNA extraction}

A total of 12 individual samples of $N$. megapotamica were collected in Itaara, Rio Grande do Sul, Brazil (Table 1) and dried at room temperature. DNA was extracted from dry leaves as described by Dellaporta et al. (1983).

\section{RAPD reactions}

The primers were selected according to the results obtained by Hanai et al. (2010) using Ocotea catharinensis (Lauraceae). A total of 11 primers were selected, based on their high polymorphic profile and good reproducibility of the generated fragments (Table 2). The amplification 
reactions were performed in an AmpliTherm TX96 Plus ${ }^{\mathrm{TM}}$ thermocycler (AmpliTherm Thermal Cycler, Madison, WI, USA). Each amplification reaction $(25 \mu \mathrm{L})$ contained $10 \mathrm{mM}$ Tris- $\mathrm{HCl}, \mathrm{pH}$ 8.3, $50 \mathrm{mM} \mathrm{KCl}, 3 \mathrm{mM} \mathrm{MgCl}$, $0.2 \mathrm{mM}$ dNTPs, $0.25 \mu \mathrm{M}$ RAPD primer (Sigma-Aldrich, St. Louis, MO, USA), $20 \mathrm{ng}$ DNA, $1.5 \mathrm{U} / \mu \mathrm{L}$ Taq DNA Polymerase (Thermo Fisher Scientific, Waltham, MA, USA), and ultra-pure water. The thermal profile consisted of an initial denaturation at $94^{\circ} \mathrm{C}$ for $5 \mathrm{~min}$, followed by 45 cycles of denaturation at $94^{\circ} \mathrm{C}$ for $1 \mathrm{~min}$, annealing at $35^{\circ} \mathrm{C}$ for $1 \mathrm{~min}$, and elongation at $72^{\circ} \mathrm{C}$ for $2 \mathrm{~min}$, with a final extension at $72^{\circ} \mathrm{C}$ for $6 \mathrm{~min}$. Amplification products were resolved by electrophoresis on $1.5 \%$ agarose gel.

\begin{tabular}{|c|c|c|c|}
\hline Sample & Latitude & Longitude & Elevation $(\mathrm{m})$ \\
\hline N1 & 2940 ' $10.10 " \mathrm{~S}$ & 5346 '19.01" W & 232.28 \\
\hline N2 & 2940 ' $12.05 " \mathrm{~s}$ & $5346^{\prime} 18.60 " \mathrm{~W}$ & 230.36 \\
\hline N3 & 2940 ' 12.62 " S & 5346 ' 18.87" W & 239.01 \\
\hline N4 & 2940 ' $12.01 " \mathrm{~S}$ & 53 46' 18.84" W & 230.84 \\
\hline N5 & 2940 ' 12.82 " S & $5346^{\prime} 19.20 " \mathrm{~W}$ & 237.09 \\
\hline N6 & 2940 ' $12.70 " \mathrm{~S}$ & $5346^{\prime} 18.41 " \mathrm{~W}$ & 242.86 \\
\hline N7 & 2940 ' $12.49 " \mathrm{~S}$ & 53 46' 18.19" W & 244.30 \\
\hline N8 & 29 40' 12.19" S & 53 46' 17.66" W & 240.93 \\
\hline N9 & $2940^{\prime} 11.89^{\prime \prime} \mathrm{S}$ & $5346^{\prime} 17.32^{\prime \prime} \mathrm{W}$ & 245.98 \\
\hline N10 & 29 40' 11.83" S & $5346^{\prime} 17.23^{\prime \prime} \mathrm{W}$ & 247.18 \\
\hline N11 & 2940 ' 11.84" S & $5346^{\prime} 17.70^{\prime \prime} \mathrm{W}$ & 242.38 \\
\hline N12 & 2940 ' 12.22 " S & 53 46' 19.42" W & 230.60 \\
\hline
\end{tabular}

Table 2. Selected random amplified polymorphic DNA (RAPD) primers used in this study for the genetic analysis of 12 Nectandra megapotamica individuals along with the number of obtained bands, number of polymorphic bands, and percentage of polymorphic bands.

\begin{tabular}{llccc}
\hline Primer & Sequence & Number of obtained bands & Number of polymorphic bands & Polymorphic bands (\%) \\
\hline OPA-02 & 5'-TGCCGAGCTG-3' & 2 & 2 & 100 \\
OPA-04 & 5'-AATCGGGCTG-3' & 11 & 11 & 100 \\
OPA-10 & 5'-GTGATCGCAG-3' & 3 & 3 & 100 \\
OPA-11 & 5'-CAATCGCCGT-3' & 9 & 9 & 100 \\
OPA-12 & 5'-TCGGCGATAG-3' & 6 & 6 & 100 \\
OPA-13 & 5'-CAGCACCCAC-3' & 11 & 11 & 100 \\
OPA-15 & 5'-TTCCGAACCC-3' & 4 & 6 & 100 \\
OPA-18 & 5'-AGGTGACCGT-3' & 6 & 6 & 100 \\
OPD-05 & 5'-TGAGCGGACA-3' & 10 & 10 & 100 \\
OPD-07 & 5'-TTGGCACGGG-3' & 10 & 10 & 800 \\
OPD-08 & 5'-GTGTGCCCCA-3' & 9 & 8 & 88.89 \\
Overall & & 81 & 80 & 98.99 \\
\hline
\end{tabular}

\section{Data analysis}

Fragment data were scored for the presence ("1") or the absence ("0") of a band using PyElph (Pavel and Vasile, 2012). The number of genetic clusters $(K)$ in the population was defined by software STRUCTURE 2.3.4 (Pritchard et al., 2000) using the admixture model default and correlated allele frequencies. Each run had a burn-in length of 500,000 followed by 500,000 Markov Chain Monte Carlo (MCMC) repetitions with 20 iterations per $K$ from $K=1$ to 12 . The optimal number of clusters was determined using the $\Delta K$ method (Evanno et al., 2005). Genetic variation was calculated by Nei's genetic distance $(h)$ and Shannon's information index $(I)$ using POPGENE 
(Yeh et al., 1997). The analysis of molecular variance (AMOVA) was calculated using Arlequin 3.5 (Excoffier and Lischer, 2010), and principal coordinates analysis (PCoA) was performed using GenAIEx 6.5 (Peakall and Smouse, 2012) to visualize the genetic relationship between clusters. The Mantel test was applied to estimate the correlation between genetic distance and geographic distance among clusters.

\section{RESULTS AND DISCUSSION}

A total of 81 bands with molecular weights ranging from 250 to 2080 bp were amplified from the 11 RAPD primers. All primers showed a high level of polymorphism and $98.99 \%$ of the bands were polymorphic (Table 2). These results indicated that these 11 RAPD markers can be reliably used for differentiating $N$. megapotamica individuals and populations. Hanai et al. (2010) identified 94 bands when they used the same RAPDs for screening in vitro cultures of Ocotea catharinensis.

The optimal value of $K$ was 3 as determined by $\Delta K$ statistic using STRUCTURE (Figure 1). The height of the $\Delta K$ values indicate the strength of the population subdivision; here, the highest value was observed for $K=3$ and a second mode for $K=4$. The standard deviation in $\operatorname{Ln} P(K)$ (data not shown) also suggested the subdivision of the population into three clusters, and these results were consistent with PCoA (Figure 2).
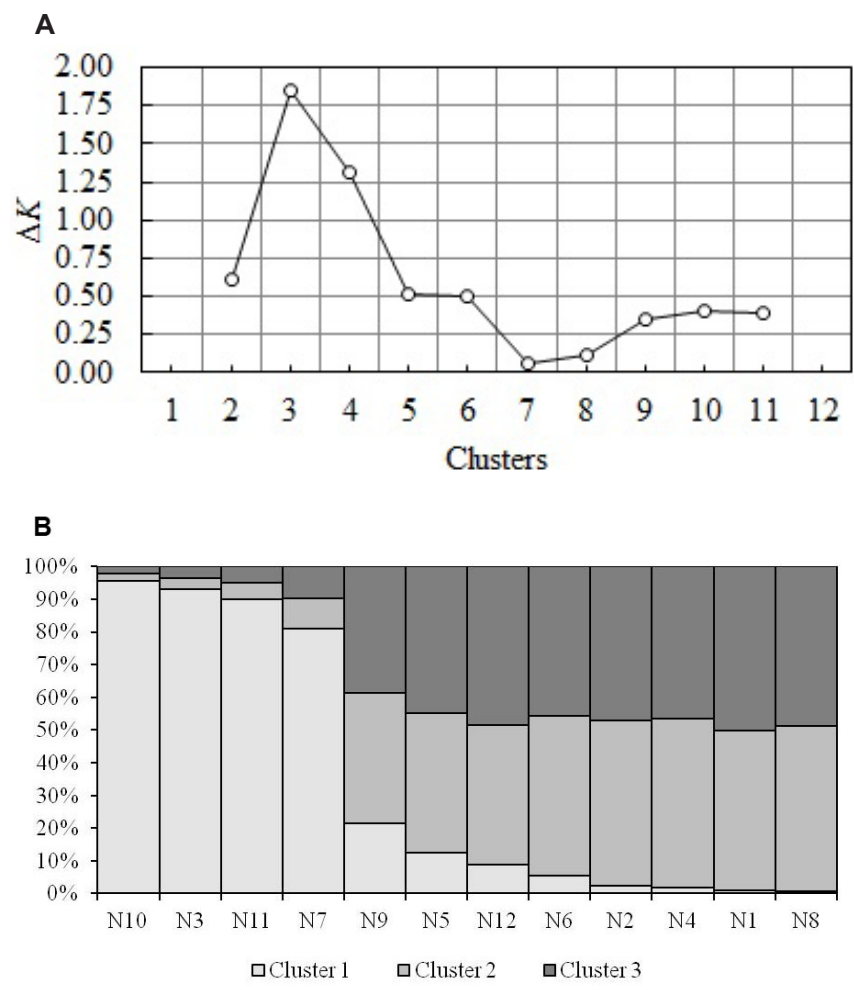

Figure 1. $\Delta K$ likelihood distribution A. Estimated population structure. B. Each individual is represented by a vertical column, which is partitioned into segments of different shades of grey that represent the individual estimated membership fractions in $\mathrm{k}$ clusters. 


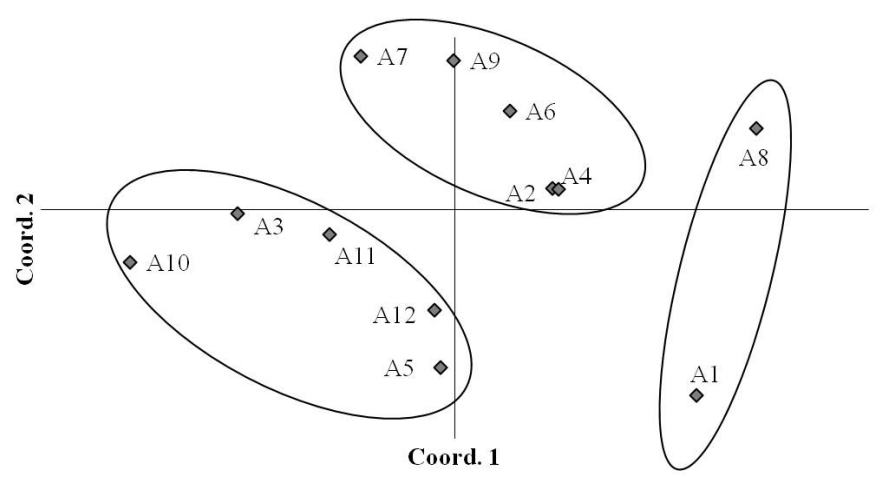

Figure 2. Genetic relationship among 12 Nectandra megapotamica individuals as determined by principal coordinate analysis (PCoA). Axis 1 accounts for $38.80 \%$ and axis 2 for $12.23 \%$ of the variation in the data.

The observed number of alleles $\left(N_{\mathrm{A}}\right)$ was 1.99, the effective number of alleles $\left(N_{\mathrm{E}}\right)$ was 1.56, $h$ was 0.33 , and I was 0.49 (Table 3 ). Using RAPD markers analysis, when compared to other tree species from the same family, the diversity in $N$. megapotamica could be considered high. Oliveira et al. (2008) found very similar results in Dimorphandra mollis $\left(N_{\mathrm{A}}=2 ; N_{\mathrm{E}}=1.51 ; h\right.$ $=0.30$; and $I=0.46$ ).

Among clusters, Nei's genetic distance ranged from 0.13 to 0.22 and Shannon's diversity index from 0.19 to 0.33 (Table 3).

Table 3. Number of individuals $(N)$ and genetic parameters of the three clusters $(K=3)$, as determined by STRUCTURE (Pritchard et al., 2000) and principle coordinates analysis, of a natural population of 12 Nectandra megapotamica individuals.

\begin{tabular}{lcccc}
\hline Parameters & Cluster 1 & Cluster 2 & Cluster 3 & Overall \\
\hline $\mathrm{N}$ & 5 & 5 & 2 & 12 \\
$\mathrm{Na}$ & $1.68(0.47)$ & $1.58(0.49)$ & $1.32(0.47)$ & $1.99(0.11)$ \\
$\mathrm{Ne}$ & $1.33(0.32)$ & $1.39(0.40)$ & $1.22(0.33)$ & $1.56(0.32)$ \\
$h$ & $0.21(0.17)$ & $0.22(0.21)$ & $0.13(0.19)$ & $0.33(0.15)$ \\
$l$ & $0.32(0.17)$ & $0.33(0.30)$ & $0.19(0.28)$ & $0.49(0.18)$ \\
$\mathrm{P} \%$ & 67.9 & 58.02 & 32.1 & 98.77 \\
\hline
\end{tabular}

$\mathrm{Na}=$ Observed number of alleles; Ne = Effective number of alleles; $h=$ Nei's genetic distance; $I=$ Shannon's information index; $\mathrm{P} \%=$ Percentage of polymorphic loci.

AMOVA indicated that the highest genetic diversity was within $(75.11 \%)$ rather than among the three clusters $(24.89 \%)$, indicating that $N$. megapotamica is allogamous (Hamrick and Godt, 1996). In several tropical tree species, the variation within populations is greater than among populations (Zucchi et al., 2005). The pattern of distribution of the genetic diversity within the population was also observed in three species of the Lauraceae family: Ocotea catharinensis (80\%), Ocotea odorifera (88\%), and Ocotea porosa (84\%) (Martins et al., 2015). Souza and Moscheta (2000) studied the breeding system of $N$. megapotamica, focusing on the flowering patterns and the synchronization of flowering, and identified the presence of an anti-selfing mechanism. Dichogamy has also been reported in other species of the Lauraceae family (Kubitzki and Kurz, 1984).

Estimates of genetic diversity among clusters $F_{\mathrm{ST}}$ using AMOVA indicated a high degree of differentiation between clusters 1 and $2(0.16, P<0.05)$ and very high differentiation between clusters 2 and $3(0.25, P<0.05)$. Between clusters 1 and 3 , no significant differentiation was 
observed $(P>0.05)$. These results showed that gene flow was independent from the geographical distribution and compatible with the hierarchical island model. The high and very high genetic differentiation observed between clusters 1 and 2, and 2 and 3, respectively, might be due to the relatively lower gene flow between individuals in these groups, as a result of a less synchronous activity of floral organs and pollinators. In O. catharinensis, O. odorifera, and O. porosa, the calculated $F_{\mathrm{ST}}$ values were relatively lower $(0.148,0.086$, and 0.116 , respectively), suggesting an effective gene flow among populations prior to habitat fragmentation (Martins et al., 2015). Zucchi et al. (2005) suggested that the variation among populations has direct conservation implications, indicating that a greater number of populations have to be sampled when the $F_{\mathrm{ST}}$ is high. On the other hand, if the $F_{\mathrm{ST}}$ value is low, a greater number of individuals by population must be sampled.

The Mantel test showed a low correlation between genetic and geographic distance among individuals $(r=0.25)$ that was not significant $(P=0.105)$, suggesting that the observed genetic differentiation was not caused by the distance. However, Zucchi et al. (2005) observed a strong spatial structure in the Eugenia dysenterica populations.

Overall, this study revealed the high levels of genetic diversity and high genetic differentiation among the three clusters. No spatial pattern of genetic diversity was observed between clusters, whereas the gene flow followed the hierarchical island model and was independent from the geographical distribution.

\section{Conflicts of interest}

The authors declare no conflict of interest.

\section{ACKNOWLEDGMENTS}

Research funded by the Conselho Nacional de Desenvolvimento Científico e Tecnológico (CNPq). We would like to thank Editage (www.editage.com.br) for English language editing.

\section{REFERENCES}

Apel MA, Lima MEL, Souza A, Cordeiro I, et al. (2006). Screening of the biological activity from essential oils of native species from the Atlantic Rain Forest (São Paulo-Brazil). Pharmacology 3: 376-383.

Bered F, Barbosa-Neto JF and Carvalho FIF (1997). Marcadores moleculares e sua aplicação no melhoramento genético de plantas. Cienc. Rural 27: 513-520.

Buckley DP, O’Malley DM, Apsit O, Prance GT, et al. (1988). Genetics of Brazil nut (Bertholletia excelsa Humb. \& Bonpl.: Lecythidaceae). Theor. Appl. Genet. 76: 923-928.

Dellaporta SL, Wood J and Hicks JB (1983). A plant DNA minipreparation: version II. Plant Mol. Biol. Rep. $1: 19-21$.

Dos Santos DF and Gilbert B (1975). The alkaloids of Nectandra megapotamica. Phytochemistry 14: 821-822.

Evanno G, Regnaut S and Goudet J (2005). Detecting the number of clusters of individuals using the software STRUCTURE: a simulation study. Mol. Ecol. 14: 2611-2620.

Excoffier L and Lischer HEL (2010). Arlequin suite ver 3.5: a new series of program to perform population genetics analyses under Linux and Windows. Mol. Ecol. Resour. 10: 564-567.

Garcez FR, Garcez WS, Hamerski L and Miguita CH (2009). Fenilpropanóides e outros constituintes bioativos de Nectandra megapotamica. Quím. Nova 32: 407-411.

Gobbo-Neto L and Lopes NP (2007). Plantas medicinais: fatores de influência no conteúdo de metabólitos secundários. Quím. Nova 30: 374-381.

Hamrick JL and Godt MJW (1996). Conservation Genetics of Endemic Plant Species. In: Conservation Genetics, Case Histories From Nature (Avise JC and Hamrick JL, eds.). Chapman and Hall, New York, 281-304.

Hanai LR, Floh EIS, Fungaro MHP, Santa-Catarina C, et al. (2010). Methylation patterns revealed by MSAP profiling in genetically stable somatic embryogenic cultures of Ocotea catharinensis (Lauraceae). In Vitro Cell. Dev. Biol. Plant 46: 368-377. 
Kubitzki K and Kurz H (1984). Synchronized dichogamy and dioecy in Neotropical Lauraceae. Plant Syst. Evol. 147: 253-266. Martins EM, Lamont RW, Martinelli G, Lira-Medeiros CF, et al. (2015). Genetic diversity and population genetic structure in three threatened Ocotea species (Lauraceae) from Brazil's Atlantic Rainforest and implications for their conservation. Conserv. Genet. 16: 1-14.

Mittermeier RA, Myers N, Thomsen JB, Da Fonseca GAB, et al. (1998). Biodiversity hotspots and major tropical wilderness areas: approaches to setting conservation priorities. Conserv. Biol. 12: 516-520.

Oliveira DL, Paula MFB, Pimenta MAS, Braga RF, et al. (2008). Variabilidade genética de populações de Fava D'Anta (Dimorphandra mollis) da região norte do estado de Minas Gerais. Rev. Árvore 32: 355-363.

Pavel AB and Vasile Cl (2012). PyElph - A software tool for gel analysis and phylogenetics. BMC Bioinformatics 13: 9.

Peakall R and Smouse PE (2012). GenAlEx 6.5: genetic analysis in Excel. Population genetic software for teaching and research-an update. Bioinformatics 28: 2537-2539.

Pritchard JK, Stephens M and Donnelly P (2000). Inference of population structure using multilocus genotype data. Genetics 155: 945-959.

Souza LA and Moscheta IS (2000). Morfo-anatomia e aspectos da biologia floral de Nectandra megapotamica (Spreng.) Mez. (Lauraceae). Acta Bot. Bras. 14: 15-25.

Yeh FC, Yang RC, Boyle TBJ, Ye ZH, et al. (1997). POPGENE, the user-friendly shareware for population genetic analysis. Molecular Biology and Biotechnology Centre, University of Alberta, Canada.

Zucchi MI, Pinheiro JB, Chaves LJ, Coelho ASG, et al. (2005). Genetic structure and gene flow of Eugenia dysenterica natural populations. Pesqui. Agropecu. Bras. 40: 975-980. 